\title{
Binding Connectivity in Copular Sentences
}

\author{
Pauline Jacobson \\ B rown University
}

\section{Copular Connectivity}

This paper takes as its point of departure the hypothesis that surface structures directly receive a model theoretic interpretation, without being mapped into (or derived from) a mediating level such as deep structure or LF. In particular, I am concerned with those cases centering around binding which are of ten thought to necessitate some kind of abstract level. Note that the standard view of binding and binding constraints is that there are two items - a binder and a bindee - and that these have to be in some particular syntactic relationship in order for binding to take place. It is, however, well known that there are many cases where on the surface the two items are not in fact in the appropriate configurational relationship - the usual solution is thus to posit some abstract level at which they are. But an alternative solution is to reject the idea that binding is a relationship between two NPs in a given syntactic configuration, and this is the view which will be taken here.

In this paper, I will concentrate on one instance of (apparently) unexpected binding effects found in specificational copular sentences. Copular sentences are particularly illuminating in this regard since they in fact exhibit a variety of connectivity effects; a few of these are sketched in (1).

\section{(1) a. Binding of reflexive within predicative constituent} What John is is proud of himself. (Higgins, 1973, etc.)

b. Binding of reflexive within an NP

What John hated was the picture of himself in the yearbook.

(Akmajian, 1970; Higgins, 1973, etc.)

c. Binding of "bare" reflexive

What the missile destroyed was itself (Peters and Bach, 1968)

Yet on the other hand, copular sentences have been particularly intractable for solutions that rely on abstract levels, for reasons which I will discuss below. This might suggest then, that the moral to be drawn from copular sentences is that it is incorrect to characterize binding phenomena in terms of a particular syntactic configuration which must or can't hold between two NPs.

Due to lack of space, I will say little about the cases in (1) (but see Sec. 6); instead I will concentrate primarily on one less commonly discussed case of unexpected connectivity in copular sentences. This was noticed in Dahl (1981) and Hornstein (1984), and is given in (2):

(2) a. The woman who every Englishman ${ }_{i}$ admires (the most) is his ${ }_{i}$ mother.

b. The only woman that no Englishman $n_{i}$ will invite to dinner is his ${ }_{i}$ mother.

Here we find a pronoun in the post-copular constituent which is (apparently) bound by a quantified NP in the relative clause in the pre-copular constituent. This is surprising for several reasons. First, it is common wisdom that - modulo certain cases involving "inverse linking" (May, 1985) and genitive NPs - a quantified NP must c-command a pronoun that it binds (Reinhart, 1983). Second, in order for the quantificational NP to bind the pronoun it would have to scope over it, yet it has been known since the work in Generative Semantics that a quantified NP can 
normally scope out of a relative clause only with great difficulty (see, e.g., Lakoff, 1970; see also Rodman, 1976). Thus note that (3) contrasts robustly with (2):

(3) a. ?*The woman who every Englishman ${ }_{i}$ likes the most killed his mother. b. ?*The woman who no Englishman ${ }_{i}$ invited to dinner killed his mother.

Third, even if a quantified NP can in some cases scope out of a relative clause, this cannot be the explanation for (2) since, as noted by Dahl (1981) assigning widest scope to the quantified NP in (2) does not actually give the right meaning. This is easiest to demonstrate with (2b); note that its meaning (or at least its most prominent meaning) is not the one paraphrased in (4):

(4) For no Englishman $x$ is it the case that the only woman that $x$ invited to dinner is $x^{\prime}$ s mother.

Finally, there is one further striking fact about this kind of binding - it appears to be sensitive to Weak Crossover effects (Hornstein, 1984). Thus note the contrast between (2) and (5):

(5) a. ?*The woman who loves every Englishman ${ }_{i}$ the most is hisi mother.

b. ?*The woman who invited no Englishman $n_{i}$ to dinner is his $i$ mother.

A plausible hypothesis here is that the contrast between (2) and (5) reduces to a runof-the-mill Weak Crossover effect as in (6a) vs. (6b):

(6) a. No Englishman ${ }_{\mathrm{i}}$ invited his mother to dinner.

b. ?*His ${ }^{\text {m mother invited no Englishman }}$ to dinner.

Thus the standard solution to unexpected connectivity effects like these is to posit either a level of representation at which the post-copular constituent is actually in the position of the gap in the pre-copular constituent, or a level at which the postcopular constituent is surrounded by a copy of the pre-copular material. The first of these is the more common approach; using (2) as the exemplar two variants of this solution are shown in (7). One is a transformational variant and is (roughly) the solution proposed in Ross (cited in Lakoff, 1965), Akmajian (1970), and others; the second is simply the backwards reconstruction variant proposed in Hornstein (1984). (It should be noted that, with the exception of Hornstein (1984), the bulk of the literature is concerned with the binding of reflexives as in (1) rather than the binding in (2); nonetheless the standard solutions proposed for (1) would generalize to (2).)

(7) a. Extraction analysis (roughly, Akmajian, 1970):

the only woman who every Englishman ${ }_{i}$ admires his mother is $\Delta$

b. Reconstruction analysis (Hornstein, 1984): the only woman who every Englishman ${ }_{i}$ admires $t_{i}$ is his mother

Obviously this gives a level at which the pronoun is c-commanded by the quantified NP without scoping out the quantified NP, and so the idea is that binding would take place at that level. Further, this could presumably account for the Weak 
Crossover facts in (5); the relevant level would exhibit a Weak Crossover violation and would, in fact, contain a structure like (6b).

However, as detailed most thoroughly in Higgins (1973), there are a number of problems with this type of solution. Perhaps the most serious and obvious is that the pre-extraction/reconstruction level appears to be semantic hash. In other words, since this is the level of representation at which binding is stated, it presumably is more generally the level which inputs the model-theoretic interpretation. Yet it is difficult to imagine any natural set of rules which would give the correct interpretation to the pre-extraction structure in (7a) or to the identical reconstruction structure in (7b). Along these lines, Higgins points out that a semantics for specificational copular sentences is needed anyway for cases like (8) in which there is no gap in the pre-copular constituent:

\section{(8) Her Christmas present was a kangaroo.}

Presumably, a sentence like (2) should be interpreted in essentially the same way that $(8)$ is, but no reconstruction nor extraction could be involved in giving the interpretation for (8).

The second type of solution - variants of which are proposed in Peters and Bach (1968) and Ross (1972) - posits that the post-copular constituent is not actually in the gap position at the relevant level. Rather, it is surrounded by a copy of the pre-copular constituent; thus the relevant level for (2) is as shown in (9):

(9) the only person who every Englishman ${ }_{i}$ admires is every Englishman $_{i}$ admires hisi mother.

Again, while this accounts for the unexpected connectivity effects, this solution too makes little semantic sense and has no motivation other than providing an account of these effects. And note that this solution too does not generalize to (8).

Moreover,, Groenendijk and Stokhof (1983) point out that this type of binding is also found in cases like (10):

(10) Every Englishman ${ }_{i}$ loves someone. It's his mother.

To extend either of the above types of solutions to (10) would be extremely complex, and best, and would involve a number of operation which appear to have no independent motivation.

\section{Variable Free Semantics}

Since the solutions relying on abstract levels appear to present serious difficulties for the rest of the semantics of copular sentences, we might instead conclude from these that binding should not be seen as a relationship between two NPs in a given syntactic configuration. I will thus argue that the binding in (2) can be naturally accounted for by an extension of the analysis of functional questions developed in Groenendijk and Stokhof (1983) and Engdahl (1986). However - and quite crucially - the functional question analysis by itself is not enough to provide a full account - my full account relies on combining this with the variable-free approach to binding argued for in Jacobson (1991, 1992a, 1992b, 1994).

We thus turn first to the variable-free account of binding explored in these papers; I will quickly review this account and some independent motivation for it. The basic idea of a variable-free approach was proposed in Quine (1966) (see also Curry and Feys, 1958) and has also been explored recently in Szabolcsi (1987, 
1992) and Hepple (1990), although my implementation is somewhat different from those. Consider first an ordinary case of binding, as in (11) and (12):

(11) Every Englishman $n_{\mathrm{i}}$ thinks (that) Mary likes himi.

(12) Every Englishman ${ }_{i}$ loves his $s_{i}$ mother.

Under the standard account of binding, the embedded $S$ in (11) translates as the open proposition Mary likes $x$; this in turn can be seen as a function from assignment functions to propositions. Similarly, the object NP in (12) translates as what we might call the "open individual" $x^{\prime} s$ mother - i.e., a function from assignment functions to individuals. Under the variable-free approach, on the other hand, there are no variables as semantic entities or as crucial parts of the semantic machinery, and so there are of course also no assignment functions. Rather, in (11) the embedded $S$ just denotes the property shown in (13):

(13) Mary-likes-him' $=\lambda x\left[\right.$ like' $\left.^{\prime}(x)(m)\right]$

In order to achieve the effect that the embedded $S$ in (11) has the meaning given in (13), we will assume first that a pronoun like him denotes just the identity function on individuals. (Actually, it presumably denotes the identity function on male individuals, but for simplicity I ignore gender here.) Leaving aside certain details which are not crucial to the points at hand, we can assume that the way in which the meaning of the embedded $S$ is put together is as sketched in (14). Here the meaning of likes first function composes with the meaning of the pronoun, so that the VP likes him just means likes'. Then the subject type-lifts and function composes with the meaning of likes, and the result is (13):

(14) likes-him' = likes' 。 him' = likes'

Mary-likes-him' $=\lambda \mathrm{P}[\mathrm{P}(\mathrm{m})]$ 。 likes' $=\lambda x\left[\right.$ likes $\left.^{\prime}(\mathrm{x})(\mathrm{m})\right]$

(Actually, in Jacobson (1994, in preparation) this is done somewhat differently; here function composition is not used directly but is instead broken down into the two steps of the Geach rule followed by functional application. The reasons for this primarily concern the way in which this system hooks into the syntax; but since the issues involved in this are orthogonal to the point here, we will simplify here and instead directly use function composition.)

Similarly, take (12). Since a pronoun denotes only the identity function on individuals, it ends up contributing nothing to the meaning and is essentially just like a gap. It follows, then, that his mother denotes just the-mother-of function. Of course to make this explicit we need to embed this into some theory of the semantics of genitives with relational nouns. Suppose, then, that we say that the ordinary common noun mother is of type $\langle\mathrm{e},\langle\mathrm{e}, \mathrm{t}\rangle\rangle$ and is of syntactic category $\mathrm{N} / \mathrm{R} \mathrm{PP}$ - that is, it wants a PP complement to its right to give a common noun. Call this mother 1 . Suppose further that we assume that any relational noun - i.e., any item of category $\mathrm{N} / \mathrm{R} P \mathrm{PP}$ - can shift its syntactic category and meaning as follows:

(15) Let $\alpha$ be an expression of category N/RPP with meaning of type $\langle e,\langle e, t\rangle\rangle$. Then there is a homophonous expression $\beta$ of category NP/LNP[GEN], with meaning of type $<e, e>$, where $\beta^{\prime}=\lambda x\left[1 y\left[\alpha^{\prime}(x)(y)\right]\right]$

Given (15), there is a second item mother 2 which denotes a function from individuals to individuals; this item is expecting a genitive NP as argument, and the full NP $x$ 's mother will thus denote the unique individual $y$ such that mother ${ }_{1}^{\prime}(x)(y)$. (In other words, mother ${ }^{\prime}$ is that function mapping each individual 
into their mother.) Now in the composition of the meaning of his mother, we have an instance of mother 2 , and this will function compose with the meaning of the pronoun (which, recall, is the identity function on individuals); the result is that his mother again denotes the function mapping an individual into their mother, as shown in (16):

(16) mother $_{2}^{\prime} \circ \lambda \mathrm{x}[\mathrm{x}]=\lambda \mathrm{x}\left[\mathrm{ly}\left[\alpha^{\prime}(\mathrm{x})(\mathrm{y})\right]\right]$ (= "the-mother-of function")

(The reader may wonder what forces function composition to apply here when the genitive is a pronoun rather than a full NP; for discussion of this see Jacobson (1994, in preparation).

Consider now the question of how it is that the pronoun eventually gets bound. Here I assume that the binding effect takes place via a type-shift rule operating on the meaning of think in (11) and on loves in (12). I have called this operation $z$; it is spelled out in (17):

(17) Let $\alpha$ be an expression with meaning of type $\langle\mathrm{X},<\mathrm{e}, \mathrm{Y}\rangle\rangle$. Then there is a homophonous expression $\beta$ with meaning of type $\langle<e, X\rangle,\langle e, Y\rangle\rangle$, were $\beta^{\prime}=z\left(\alpha^{\prime}\right)$. The definition of $z$ is: For any function $g, z(g)=$ $\lambda f[\lambda x[g(f(x))(x)]]$ (for $f$ a variable of type $<e, X>$ ).

This can be straightforwardly generalized for the case of 3-place verbs; see Jacobson (1992a). The effect of the $z$ rule is to "bind" the pronoun in some argument of a verb to a higher argument slot of that verb. For example, take the case of love, which denotes an ordinary 2-place relation between individuals. It can shift by $z$ to denote a relation between individuals and functions from individuals to individuals, such that to $z$ (love) some function $\mathrm{f}$ is to be an $\mathrm{x}$ who stands in the ordinary loves' relation to $\mathrm{f}(\mathrm{x})$.

We can exemplify with (12). We have seen that the object NP his mother denotes just the-mother-of function, and so is of the right type to serve as object of $z$ (loves'). (12) thus says that every man $z$ (loves) the-mother-of function. The binding in (11) is similar. Here the ordinary meaning of think is a relation between individuals and propositions, but in (11) it shifts by $z$. Note that $z$ (think') is a relation between individuals and properties such that to $z$ (think) a property $P$ is to be an $x$ who thinks that $x$ has $P$. Since the embedded $S$ in (11) denotes the property of being liked by Mary (as shown in (14)) it can serve as the object here, and (11) says that every man stands in the $z$ (think') relation to that property. The binding effect in both (11) and (12) is sketched more explicitly in (18):

(18) a. Every Englishman loves his $_{i}$ mother' $(=(12))$ :

$z\left(\right.$ loves' $\left.^{\prime}\right)=\lambda \mathrm{f}\left[\lambda \mathrm{x}\left[\right.\right.$ love' $\left.\left.^{\prime}(\mathrm{f}(\mathrm{x}))(\mathrm{x})\right]\right]$

loves-his-mother' $=z\left(\right.$ love $\left.^{\prime}\right)($ the-mother-of' $)=$ $\lambda x\left[\right.$ love' $^{\prime}($ the-mother-of'( $\left.(x))(x)\right]$

every-Englishman-loves-his-mother' = every-Englishman' $\left(\lambda x\left[\right.\right.$ love' $^{\prime}($ the-mother-of' $\left.\left.(x))(x)\right]\right)$

b. Every Englishman thinks (that) Mary likes him $_{i}(=(11))$ :

$z$ (thinks' $)=\lambda P\left[\lambda x\left[\right.\right.$ think' $\left.\left.^{\prime}(\mathrm{P}(\mathrm{x}))(\mathrm{x})\right]\right]$

thinks-that-Mary-likes-him' $=z\left(\right.$ think' $\left.\left.^{\prime}\right)\left(\lambda x\left[\operatorname{like}^{\prime}(x)(\mathrm{m})\right]\right]\right)=$ $\lambda x\left[\operatorname{think}^{\prime}\left(\operatorname{like}^{\prime}(\mathrm{x})(\mathrm{m})\right)(\mathrm{x})\right]$

every-Englishman-thinks-(that)-Mary-likes-him' = every-Englishman' $\left(\lambda x\left[\operatorname{think}^{\prime}\left(\operatorname{like}^{\prime}(x)(m)\right)(x)\right]\right)$ 
There are two aspects of this analysis which will play a key role in the analysis of connectivity in copular sentences. The first is that a pronoun contributes essentially nothing to the meaning of an expression in which it is located, and so any constituent containing a pronoun denotes a function from individuals to whatever type of meaning that constituent would have if it contained a full NP in place of that pronoun. The second key aspect has to do with the location of the binding effect. This effect is located in the type-shift rule which operates on an expression which wants two arguments - one argument being the pronouncontaining constituent and the other being some higher argument. Moreover, this rule will bind the pronoun within the lower argument to the higher argument slot. Crucially, then, binding is not a relationship between two NPs, but rather between argument slots.

It should also be pointed out that although this account does need the special $z$ rule in order to effect binding, any account of binding actually needs some special rule. Take, for example, one way to implement binding under a standard Montague style approach. One possibility for how binding occurs in (12) under such an approach is that the VP translates as the open property shown in (19a) and this is then mapped into the closed property shown in (19b); this then occurs as argument of the subject:

(19) a. loves-his-mother' $=$ love' $($ the-mother-of $(\mathrm{x}))===>$ (Binding rule)

b. $\lambda x$ [love-(the-mother-of'(x))(x)]

An alternative is that the subject NP is first "pulled out" and replaced by a variable which is identical to the translation of his; this variable is then $\lambda$-abstracted over and the entire expression occurs as argument of the "raised" quantified NP. Note that this too makes use of a special rule to effect binding; under this approach that rule is the $\lambda$-abstraction step.

Thus any approach would appear to need some special rule in order to effect binding. The important difference between my account and the more standard approaches sketched above is (apart from the issue of the existence of variables) in the location of the binding effect. Under the account here this is located in a shift on the meaning of likes rather than on a shift on the meaning of the full VP likes his mother (or on the meaning of a full $\mathrm{S}$ after $\mathrm{QR} x$ likes $x$ 's mother). The binding effect is, thus, located much more locally, and this will turn out to be one of the key advantages to this account in accounting for a wide array of facts (see also Jacobson (1994; in preparation) for discussion).

Notice that we can also now account for standard cases of Weak Crossover under this approach without recourse to any co-indexation conventions or any other constraints on syntactic representations such as LF. Although there are a number of well-known mysteries and open questions about Weak Crossover, let us say as a first approximation that this effect is the result of the fact that the only binding rule is the one given in (17) (generalized to 3-place verbs), where this rule has the effect of binding the pronoun to a higher argument slot. In other words, let us assume that there is no "backwards" version of (17) as given in (20), where (20) has the effect of binding a pronoun in a some argument to a lower argument slot. (Note that (20) is the Curry and Feys (1958) combinator S.)

(20) Given any expression $\alpha$ with meaning of type $\langle e,\langle X, Y\rangle\rangle, \alpha$ can shift to a homophonous expression $\beta$ with meaning of type $\langle e,\langle<e, X>>>$, where $\beta^{\prime}=s\left(\alpha^{\prime}\right)$. The definition of $s$ is: For any function $g, s(g)=\lambda x[\lambda f[g(x)(f(x))]]$ (for $f$ a variable of type $<e, X>$ ). 
If there were the operation $s$ in (20) then indeed we could get typical Weak Crossover violations such as (21):

(21) ${ }^{*} \mathrm{His}_{\mathbf{i}}$ mother loves every Englishman ${ }_{\mathbf{i}}$.

To see why this is so, let us assume that quantified NPs in object position are handled as in Partee and Rooth (1983), where loves is listed in the lexicon as being of type $\langle e,\langle e, \downarrow\rangle\rangle$ but it can argument lift on the object position so as to take a generalized quantifier in that position. Then, if we first applied $s$ to loves and then argument-lifted on the object position of $s$ (loves') we would get (21), as shown in (22):

(22) loves' --> $s\left(\right.$ loves') $=\lambda x\left[\lambda f\left[\right.\right.$ loves' $\left.\left.^{\prime}(\mathrm{x})(\mathrm{f}(\mathrm{x}))\right]\right]$

argument lift $s($ loves') on object slot: $-->\lambda P[\lambda g[P(\lambda y[s($ love' $)(y)(g)])]]=$

$\lambda P\left[\lambda \mathrm{g}\left[P\left(\lambda \mathrm{y}\left[\lambda \mathrm{x}\left[\lambda \mathrm{f}\left[\right.\right.\right.\right.\right.\right.$ loves' $\left.\left.\left.\left.\left.\left.^{\prime}(\mathrm{x})(\mathrm{f}(\mathrm{x}))\right]\right](\mathrm{y})(\mathrm{g})\right]\right)\right]\right]=$

$\lambda P\left[\lambda g\left[P\left(\lambda x\left[\right.\right.\right.\right.$ loves' $\left.\left.\left.\left.^{\prime}(\mathbf{x})(\mathrm{g}(\mathrm{x}))\right]\right)\right]\right]$

loves-every-man' $=\lambda P\left[\lambda g\left[P\left(\lambda x\left[\right.\right.\right.\right.$ loves' $\left.\left.\left.\left.^{\prime}(\mathrm{x})(\mathrm{g}(\mathrm{x}))\right]\right)\right]\right]($ every-man' $)=$

his-mother-loves-every-man' $\lambda \mathrm{g}\left[\right.$ every-man' $\left(\lambda x\left[\right.\right.$ loves' $\left.\left.\left.^{\prime}(\mathrm{x})(\mathrm{g}(\mathrm{x}))\right]\right)\right]$

$\lambda \mathrm{g}\left[\right.$ every-man' $\left.\left(\lambda \mathrm{x}\left[\operatorname{loves}^{\prime}(\mathrm{x})(\mathrm{g}(\mathrm{x}))\right]\right)\right]($ the-mother-of' $)=$ every-man' $\left(\lambda x\left[\right.\right.$ loves' $^{\prime}(x)($ the-mother-of'(x))])

But by ruling out the $s$ operation, we preclude this derivation (and any other conceivable way to get (21)). The important point, then, is that both the binding effect and any constraints on this effect is handled by a relationship between argument slots rather than a relationship between actual NPs and/or variables. Weak Crossover effects, then, are simply the result of constraints on the type-shift rule(s) that effect binding rather than a constraint on co-indexation. It should be noted, however, that in this account it is just a stipulation that "forwards" binding is possible by the $z$ rule but that there is no corresponding "backwards" $s$ rule; note that the latter is just as easy to state. Thus at this point I have no deep explanation for Weak Crossover effects, although see Dowty (1992) for relevant discussion.

\section{Independent Motivation}

A variety of independent motivation for this approach is provided in Jacobson (1991, 1992a, 1992b, 1994); in these papers I motivate this approach by a consideration of (i) functional questions; (ii) answers to functional questions; (iii) unexpected inferences of the sort discussed in Chierchia (1990), Reinhart (1990), and Higginbotham (1992); (iv) paycheck pronouns, Bach-Peters' sentences, and the interaction of these with Weak Crossover effects that were originally noticed in Jacobson (1977); (v) antecedent contained deletion; (vi) Across-the-Board binding in coordinate constructions (including Right Node Raising constructions), and (vii) i-within-i effects. Obviously space precludes a review of all of these arguments here. I will, however, review the first three since they interact robustly with the account of connectivity in copular sentences.

The first piece of motivation for this approach, then, is that the analysis of functional questions proposed in Groenendijk and Stokhof (1983) and Engdahl (1986) can be subsumed under the general mechanisms for binding. Thus consider a functional question like (23a) on the reading where (23b) is an appropriate answer: 
(23) a. Who did every Englishman invite? b. His mother.

Under the Groenendijk and Stokhof / Engdahl analysis, the meaning for (23a) is roughly as shown in (24) (note that this is rough and that a full rendering of the meaning requires embedding this into a theory of the semantics of questions; since the correct semantics of questions is orthogonal to the points here I will not do this):

(24) what is the function $\mathrm{f}$ (of type $<\mathrm{e}, \mathrm{e}>$ ) such that: every-Englishman' $\left(\lambda x\left[\right.\right.$ invite' $\left.\left.^{\prime}(\mathrm{f}(\mathrm{x}))(\mathrm{x})\right]\right)$

I assume that this meaning is correct; but where I will depart from Groenendijk and Stokhof / Engdahl is in the way in which this meaning is put together. Groenendijk and Stokhof and Engdahl both assume that the gap - or trace- has a complex meaning; it translates as a variable $f$ over functions of type $<e, e>$ applied to a variable $\mathrm{x}$ over individuals. The $\mathrm{x}$ variable is bound by the subject in the normal way that binding takes place. Then, presumably, the variable $f$ is $\lambda$-abstracted over and the entire expression is taken as argument of the question pronoun, as shown in (25) (again, the details of this last step will depend in part on one's general analysis of questions, but will not affect the points here):

(25) who' $(\lambda f[$ every-Englishman' $(\lambda x[$ invite' $(f(x))(x)])$

Notice that here we have to allow for a question pronoun to by polymorphic; it can take as argument either something of type $<e, t>$ or, in the case of functional questions, it takes as argument something of type $\langle<e, e>, t>$. This will be true in my analysis as well.

There is, however, one unpleasant aspect of this analysis, at least under treatments of extraction in Categorial Grammar. This concerns the meaning of the gap: it has to receive the complex translation $f(x)$. And crucially this is needed if one adopts a standard account of binding. The reason for this is straightforward: recall that under standard approaches to binding the variable over individuals which is ultimately "bound" by every Englishman must be present in the translation of the constituent which undergoes the binding rule. In other words, we need either a VP which translates as invite' $(f(x))$ or a full sentence of the form invite $(f(x))(x)$ in order to $\lambda$-abstract over the variable $x$ in such a way that it will be bound.

But consider the analysis of extraction in most recent versions of Categorial Grammar. While there are a variety of such analyses (Steedman, 1987; Jacobson, 1987; Moortgat, 1989; Oehrle, 1990), all have in common the claim that a gap has no meaning at all - it is simply the failure of an expected argument to be introduced in the normal way. There is, then, no way that it could possibly have this complex meaning.

But given the approach to binding sketched above, the gap in a functional question is just like any other gap - it is just a missing argument which in this case happens to be an argument of type $<\mathrm{e}, \mathrm{e}\rangle$. In other words, all we need to say is that invites shifts by $z$ and is therefore expecting an argument of type $\langle e, e>$. Hence the question asks for the identity of the function $\mathrm{f}$ such that every Englishman $z$ invites $\mathrm{f}$. (26) thus sketches how the meaning of (23 is put together under a Steedman-style approach to extraction:

(26) invite' $=\boldsymbol{z}\left(\right.$ invite' $\left.^{\prime}\right)=\lambda \mathrm{f}\left[\lambda \mathrm{x}\left[\right.\right.$ invite' $\left.\left.^{\prime}(\mathrm{f}(\mathrm{x}))(\mathrm{x})\right]\right]$

every-Englishman-invite' $=$ every-Englishman' $\mathrm{o} z\left(\right.$ invite' $\left.^{\prime}\right)=$

$\lambda f\left[\right.$ every-Englishman' $\left(\lambda x\left[\right.\right.$ invite' $\left.\left.\left.^{\prime}(\mathrm{f}(\mathrm{x}))(\mathrm{x})\right]\right)\right]$

(this then occurs as argument of the question pronoun) 
Thus there is no need to say anything special about the gap here or treat it in any different way from an ordinary gap; the fact that it can be a "functional" gap is simply a result of the way in which variable binding works in general. It should, of course, be noted that - just as in the Groenendijk and Stokhof / Engdahl analysis there is one aspect which does not come completely "for free" - this analysis (like theirs) will require question pronouns to be polymorphic. However, the rest follows directly from the normal binding mechanisms, and so functional questions are perfectly compatible with Categorial accounts of extraction in general.

Moreover, we also immediately account for the interaction of Weak Crossover and functional questions discussed in Chierchia $(1990,1993)$. Thus May (1985) and Chierchia point out that (27) lacks a functional reading, and Chierchia (1990) points out that, given the functional question analysis, this should reduce to Weak Crossover:

(27) *Who invited every Englishman? His mother.

While I take Chierchia's basic point to be correct, it is worth noting that the actual mechanism which he invokes to perform this reduction is somewhat complex. Since he takes Weak Crossover to be a constraint on indexing at some level of representation, he must provide a functional gap with two indices (one corresponding to the variable over functions, and one corresponding to the variable over individuals). But again the impossibility of the functional reading in (27) follows in this account from the absence of the backwards binding rule $s$. As detailed in (22), the existence of such a rule would allow the VPin (27) to have the functional reading shown in (28), and this could then occur as argument of the question pronoun:

(28) invite-every-Englishman':

lift on object position of $s$ (invite') and then apply to every-man' $=$ $\lambda f\left[\right.$ every-Englishman' $\left(\lambda x\left[\right.\right.$ invite $\left.\left.\left.^{\prime}(x)(f(x))\right]\right)\right]$

But the absence of $s$ blocks this (or any other conceivable derivation to give rise to the functional reading); thus the lack of a functional reading follows from the fact that a functional argument cannot be bound to a lower argument slot.

The second advantage of this approach to binding is even more striking; this centers on the fact that his mother is a perfectly good answer to a functional question like (23a). In fact, under the standard approach to binding this is quite surprising - the meaning of his mother ought to be the "open individual" $x$ 's mother - which is just an individual relative to some way to assign values to the variables. Yet the question does not ask for the identity of an individual (nor for the identity of a function from assignment functions to individuals); it asks for the identity of a function from individuals to individuals.

But here the fact that his mother is an appropriate answer is unsurprising. since the pronoun his denotes the identity function, his mother just means themother-of-function, and so of course it is of the right type to be the answer to a functional question. This point is also discussed in Gawron and Peters (1990) and Ginzburg (1992), and both posit a special rule which maps the meaning of certain NPs into functions of the right type in order to account for this. Here, however, no such extra rule is needed. The fact that his mother automatically denotes a function of type $\langle e, e\rangle$ in this account will become crucial below.

The third advantage that we will consider here centers on cases of unexpected inferences of the sort discussed in Chierchia (1990), Reinhart (1990), Higginbotham (1992), and others. This phenomena is exemplified in (29): 
(29) a. Every Englishman believes whatever every Frenchman believes.

b. Every Frenchman ${ }_{i}$ believes that he $e_{i}$ should drink red wine.

c. Therefore, every Englishman ${ }_{j}$ believes that he ${ }_{j}$ should drink red wine.

As detailed in Chierchia (1990), the fact that we get what we might call here the "sloppy" inference is unexpected under standard accounts of binding. Chierchia's solution, thus, was to attribute this to a special lexical property of the verb believe; more generally, he tried to tie this in to Lewis' account of de se belief. However, this account is quite thoroughly critiqued in Reinhart (1990). I won't repeat her full arguments here save to point out that, as she notes, this phenomenon has nothing to do with belief, for we get this quite generally. For example, we find the parallel inference in a case like (30):

(30) a. Every Englishman loves whoever every Frenchman loves.

b. Every Frenchman loves his $_{i}$ mother.

c. Therefore, every Englishman ${ }_{j}$ loves $_{\text {his }} \mathrm{j}_{\mathrm{j}}$ mother.

And in fact, although (31) is perhaps slightly odder, here too we can get the "sloppy" inference:

(31) a. Every Englishman loves the woman that every Frenchman loves.

b. Every Frenchman ${ }_{i}$ loves his $s_{i}$ mother.

c. Therefore, every Englishman ${ }_{j}$ loves $_{\text {his }} j_{j}$ mother.

Under the approach to binding here, these inferences follow straightforwardly provided we make only the assumption that the objects in (29a) (31a) can have functional readings. Take, for example, (31) whose semantics is sketched informally in (32):

(32) a. Every Englishman $z$-loves the function $\mathrm{f}$ (with range women) such that every Frenchman $z$-loves $f$.

b. Every Frenchman $z$-loves the-mother-of function.

c. Therefore, every Englishman $z$-loves the mother-of function.

Hence, the only apparatus needed in addition to the normal binding apparatus is some way to get the object NP to denote a function rather than an individual. (In fact, it is probably a happy result that something extra is needed in order to induce the "sloppy inference" reading, because these are indeed somewhat unusual, and we do a bit of a double-take on hearing them.) This result can be obtained by simply allowing the relative pronoun, the head noun, and the determiner to be polymorphic.

To clarify, we need to allow the object NP in (32a) to have the meaning shown in (33):

(33) the-woman-who-every-Frenchman-loves' = If $\left[\forall x\left[\operatorname{woman}^{\prime}(f(x))\right] \wedge\right.$ every-Frenchman' $(z($ loves' $\left.)(f))\right]$

As discussed earlier, the meaning of every Frenchman loves can be put together as shown in (34); this just invokes the $z$ rule combined with a Steedman style approach to extraction:

(34) every-Frenchman-loves' = every-Frenchman' o $z$ (loves' $)=$ $\lambda \times[$ every-Frenchman'(z(loves')(f))] 
As to the rest of the derivation, consider first the manning of the relative pronoun. Presumably, a relative pronoun like who normally takes as arguments two sets of individuals and returns the intersection of these sets. Thus we can just generalize this here as shown in (35) so that who takes as arguments two sets of functions from individuals to individuals, and again it returns the intersection of these sets.

(35) normal who' (of type $<<e, t>,<<e, t>,<e, t>>>$ ): $\lambda P[\lambda Q[\lambda x[P(x) \wedge Q(x)]]$ additional meaning: of type $<<f, t>,<<f, t>,<f, t>>>$ (for $f$ an abbreviation of $<\mathrm{e}, \mathrm{e}>$ ):

$\lambda A[\lambda B[\lambda f[B(f) \wedge A(f)]]$ (for $A$ and $B$ variables of type $<f, \downarrow)$

In fact, one might assume more generally that who' is of type $<<\mathrm{X}, \mathrm{t}\rangle,<<\mathrm{X}, \mathrm{t}>,<\mathrm{X}, \mathrm{t}>>>$ with meaning $\lambda \mathrm{Z}[\lambda \mathrm{Y}[\mathrm{Z} \wedge \mathrm{Y}]]$, for $\wedge$ the generalized $\wedge$ of Partee and Rooth (1983)). Thus when who' combines with the meaning of every Frenchman loves we get the meaning shown in (36):

(36) $\lambda \mathrm{B}\left[\lambda \mathrm{f}\left[\mathrm{B}(\mathrm{f}) \wedge\right.\right.$ every-Frenchman' $\left(z\left(\right.\right.$ loves' $\left.\left.\left.^{\prime}(\mathrm{f})\right)\right]\right]$

Next, we need to assume that while woman' normally denotes a common noun which characterizes a set of individuals, it too has a secondary meaning in which it denotes a set of functions - in particular, the set of functions into women. This is shown in (37):

$$
\begin{aligned}
& \text { woman' - normal meaning of type }<e, t> \\
& \text { additional meaning of type }<<e, e>, t>=\lambda g\left[\forall x\left[\operatorname{woman}^{\prime}(g(x))\right]\right]
\end{aligned}
$$

This then will be the argument of the relative clause who every Frenchman loves, and this means that the entire constituent woman who every Frenchman loves will denote the intersection of the set of functions with range women and the set of functions $f$ such that every Englishman $z$-loves $f$. Finally, this combines with the determiner the, which maps this into the unique function in that set (hence the also must be polymorphic); the derivation of the meaning of the entire NP, then, is shown in (38):

(38) woman-who-every-Frenchman-loves' =

$\lambda \mathrm{B}\left[\lambda \mathrm{f}\left[\mathrm{B}(\mathrm{f}) \wedge\right.\right.$ every-Frenchman' $\left(z\left(\right.\right.$ loves' $\left.\left.\left.\left.^{\prime}\right)(\mathrm{f})\right)\right]\right]\left(\lambda \mathrm{g}\left[\forall \mathrm{x}\left[\right.\right.\right.$ woman' $\left.\left.\left.^{\prime}(\mathrm{g}(\mathrm{x}))\right]\right]\right)=$ $\lambda f\left[\forall x\left[\right.\right.$ woman' $\left.^{\prime}(\mathrm{f}(\mathrm{x}))\right] \wedge$ every-Frenchman'(z(loves')(f) $\left.)\right]$ the-woman-who-every-Frenchman-loves' = if $\left[\forall x\left[\right.\right.$ woman' $\left.^{\prime}(\mathrm{f}(\mathrm{x}))\right] \wedge$ every-Frenchman'(z(loves')(f))]

I will leave it open as to just how general are the rules which allow the relative pronoun and the head noun to have this polymorphism.

Again, the key point is that very little extra is needed to get the kind of inferences shown above - most of this account follows from the existence of the $z$ rule and, more particularly, from the fact that binding is located on the type-shift rule operating on the meaning of loves, believes, etc. (hence we do not need to invoke a special lexical property as Chierchia does and can thus account for the generality of this phenomenon). Notice that we can use this same kind of apparatus to account for the connectivity effects across sentences discussed earlier in (10). Here we need only let someone shift into a functional reading, so that (10) says that every Englishman $z$-loves some function, and the second sentence identifies this as the-mother-of function. 


\section{The Account of Binding in Copular Sentences}

With the apparatus sketched above, we now have all of the pieces to account for the apparently problematic binding in (2); we will exemplify with (2a):

(2a) The woman who every Englishman ${ }_{i}$ loves is his $i_{i}$ mother.

Informally, the analysis is as follows. The pre-copular constituent denotes the function $f$ with range women such that every Englishman $z$-loves $f$, and the postcopular constituent identifies this as the-mother-of function. With regards to the meaning of the pre-copular constituent, note that nothing new is needed to get this meaning - the claim that this NP can have a functional meaning was motivated independently in order to account for the unexpected inference in (31). Moreover, this meaning comes almost for free under this approach to binding - the only additional apparatus needed to allow for this meaning was to allow the relative pronoun, the determiner and the head to by polymorphic so as to allow the entire NP to denote a function from individuals to individuals.

The claim that the pre-copular constituent can have a functional reading is, perhaps, not a particularly earth-shattering one, for one can see this as a straightforward extension of the Engdahl / Groenendijk and Stokhof analysis of functional questions (although, as noted earlier, it has the additional advantage of not needing to assign a complex meaning to the gap). But the key advantage of the present approach is that the functional question analysis in and of itself still leaves it mysterious as to how the post-copular constituent - his mother - has the right kind of meaning to be identified with a function of type $<e, e>$. Again, though, this follows immediately from the variable-free approach; since a pronoun is much like a gap (modulo its gender contribution) it follows that his mother denotes the-mother-of function. The moral, then, is that it is a misnomer to think of every Englishman as binding the pronoun, and so no reconstruction level is needed at which these two constituents are in an appropriate configurational relationship. The appearance of binding is due to the fact that the-mother-of function is equated with the function identified by the pre-copular constituent, and that constituent denotes the function $\mathrm{f}$ such that every Englishman $z$-loves $\mathrm{f}$. It thus follows by the normal rules of inference that every Englishman does indeed love his mother.

To complete the analysis, we will formalize it using the semantics for specificational copular sentences which is implicit in Higgins (1973), was further developed in Williams (1983), and was formalized in Partee (1985). (It should be noted, though, that any other reasonable semantics for specificational copular sentences would appear to do just as well.) According to this analysis, in both specificational and run-of-the-mill predicational sentences, be takes two arguments: one of type $<\mathrm{X}, \mathrm{t}\rangle$ and one of type X. Moreover, its meaning is such that it says that the argument of type $\mathrm{X}$ is a member of the set characterized by the other constituent. In predicational sentences, be takes the $\langle\mathrm{X}, \mathrm{t}\rangle$ argument first and to its right, and thus it is of type $\langle<\mathrm{X}, \mathrm{t}\rangle,\langle\mathrm{X}, \mathrm{t}\rangle\rangle$ and denotes the identity function. In specificational sentences, on the other hand, the $\langle\mathrm{X}, \mathrm{t}\rangle$ argument occurs to the left of $b e$ and the argument of type $\mathrm{X}$ to the right. Williams and Partee differ in their analysis of the order in which be combines with its arguments in specificational sentences; for convenience I will follow Partee here although nothing hinges on this. (The difference affects only the syntax and not the semantics.) Thus in Partee's analysis the specificational be combines first with the argument of type X (and takes this argument to its right) and then with the $<\mathrm{X}, \mathrm{t}>$ argument, and so its meaning in this case is $\lambda \times[\lambda \mathrm{P}[\mathrm{P}(\mathrm{x})]]$.

Consider now an ordinary specificational copular sentence such as (39): 
(39) The thing which John ate was the apple.

Under Partee's analysis, the thing which John ate must be of type $\langle e, t>$, even though it is an ordinary NP. To this end, Partee further proposes a type-shift rule allowing any NP (such as a definite NP) whose meaning is of type e to shift into a meaning of type <e,t> by the operation IDENT, as follows:

(40) $\operatorname{IDENT}(\mathrm{a})=\lambda x[\mathrm{x} \equiv \mathrm{a}] \quad$ (Note that $\equiv$ here is simply the more usual "="; I am using $\equiv$ to distinguish this from my use of the symbol " $="$ in showing semantic equivalences.)

(Note that an NP shifted by IDENT is guaranteed to characterize a singleton set.) Partee's full analysis of the semantics of (39), then, is as shown in (41):

(41) the-thing-which-John-ate' $=\mathbf{x}\left[\right.$ thing $^{\prime}(\mathrm{x}) \wedge$ ate' $\left.(\mathrm{x})(\mathrm{j})\right] \quad--->($ IDENT $)$

$\lambda y\left[y \equiv \operatorname{cx}\left[\right.\right.$ thing $^{\prime}(x) \wedge$ ate $\left.\left.^{\prime}(x)(j)\right]\right]$

be-the-apple' $=\lambda x[\lambda P[P(x)]]$ (the-apple' $)=\lambda P\left[P\left(\right.\right.$ the-apple' $\left.\left.^{\prime}\right)\right]$

the-thing-which-John-ate-was-the-apple' $=$ $\lambda y\left[y \equiv \operatorname{lx}\left[\right.\right.$ thing $^{\prime}(x) \wedge$ ate $\left.\left.(x)(j)\right]\right]($ the-apple $)=$ the-apple' $\equiv \mathbf{x}\left[\right.$ thing $^{\prime}(x) \wedge$ ate' $\left.(x)(j)\right]$

This analysis generalizes straightforwardly to the case where the pre-copular constituent has a functional reading, as in (2a). Here the pre-copular constituent denotes a function of type $\langle e, e\rangle$, but we will let it shift by Partee's IDENT to denote a function characterizing a set of such functions; in particular it characterizes the (singleton) set of functions identical to the original function. It can thus be predicated of the-mother-of function, which is the meaning of the post-copular constituent. The full derivation for (2a), then, is sketched in (42):

(42) the-woman-who-every-Englishman-loves' = If $[\forall x[$ woman'(f(x))] ^ every-Eng'(z(love')(f)] (see (33)-(38))

-->(IDENT): $\lambda \mathrm{g}\left[\mathrm{g} \equiv\right.$ if $\left[\forall \mathrm{x}\left[\right.\right.$ woman' $\left.^{\prime}(\mathrm{f}(\mathrm{x}))\right] \wedge$ every-Eng' $\left(z\left(\right.\right.$ love' $\left.\left.\left.^{\prime}\right)(\mathrm{f})\right]\right]$ is-his-mother' $=\lambda \mathrm{A}[\mathrm{A}$ (the-mother-of')] (for $\mathrm{A}$ a variable of type $\langle<\mathrm{e}, \mathrm{e}\rangle, \mathrm{t}\rangle$ the-woman-who-every-Englishman-loves-is-his-mother' =

$\lambda \mathrm{g}\left[\mathrm{g} \equiv \operatorname{\mathrm {ff}}\left[\forall \mathrm{x}\left[\right.\right.\right.$ woman' $\left.^{\prime}(\mathrm{f}(\mathrm{x}))\right] \wedge$ every-Eng'(z(love')(f)] $($ the-mother-of' $)=$ the-mother-of' $\equiv \operatorname{lf}\left[\forall x\left[\right.\right.$ woman' $\left.^{\prime}(\mathrm{f}(\mathrm{x}))\right] \wedge$ every-Eng' $\left(z\left(\right.\right.$ love' $\left.\left.^{\prime}\right)(\mathrm{f})\right]$

Finally, we can note that although the Weak Crossover effect shown in (5) at first glance appears to necessitate a reconstruction level in order to block coindexing, we can now account for this too without recourse to any such level nor to any indexing conventions:

(5a) ?*The woman who loves every Englishman $n_{i}$ the most is his ${ }_{i}$ mother.

Again, the lack of the backwards binding rule $s$ means that the relative clause who loves every Englishman cannot have the functional reading shown in (43):

(43) $\lambda f\left[\right.$ every-man' $\left.\left(\lambda x\left[\operatorname{loves}^{\prime}(x)(f(x))\right]\right)\right]$

Consequently, the NP the woman who loves every Englishman cannot denote the unique function $\mathrm{f}$ with range women such $\mathrm{f} s$-loves every Englishman, and thus the relevant reading for (5a) is impossible. Hence an abstract level is needed neither for 
the unexpected binding effect in (2), nor for the account of the lack of a parallel reading for (5).

\section{Salient Functions}

While the semantics shown in (42) appears at first glance to be a reasonable rendering of the meaning of (2), there is in fact an apparent subtle problem here. Consider for example (45) under the scenario in (46):

(45) The only woman that every Englishman ${ }_{i}$ invited was his mother.

(46) Englishmen are Bill, John, and Tom.

Betty is the mother of Bill.

Jane is the mother of John.

Tara is the mother of Tom.

Bill invites only Betty (his mother).

John invites only Jane (his mother).

Tom invites Tara (his mother) and Jane.

In this context, I think that we can truthfully say (45) - especially with heavy stress on every Englishman. However, given the semantics in (42), (45) should actually be false. The semantics developed above says that the only function $f$ such that every Englishman $z$ (invited) $f$ is the-mother-of function. But actually, there are two such functions: there is the-mother-of function, and there is the function mapping Bill to Betty, John to Jane, and Tom to Jane. In fact, without any further restriction on what constitutes a function, then in the case where the quantified NP is every Englishman, the semantics developed above gives exactly the same (incorrect) result as does a semantics which scopes out every Englishman.

The solution, I suspect, lies in the notion of what we are willing to countenance as a function; it must be some "natural" or salient function and not any random pairing will count as a function. (See Chierchia, 1993 for similar remarks regarding functional questions.) Because the second of the functions named above is nothing more than a random pairing of individuals, it doesn't serve to counterexemplify the claim that there is only one function $f$ such that every Englishman failed to $z$ (invite) $f$. Just how to pin down what counts as a function is a question which I will have to leave open here; it certainly is not the case that the only functions which "count" are those like the-mother-of function which are given to us by nature. We can perfectly well speak of complex functions, as in (47):

(47) The only woman that every Englishman ${ }_{i}$ invited was the one he $e_{i}$ had been hoping would teach him the mysteries of Zen.

Nonetheless, it seems reasonable to say that the only things which count as functions here are ones which we can conceive of in some way above and beyond random pairings. As support for this claim, notice that if there is in fact more than one natural pairing in the discourse context set up in (46) then (45) indeed becomes false. Suppose, for example, that all of the facts in (46) are true, but that it is also the case that Betty is the teacher of Bill, Jane is the teacher of John, and Jane is also the teacher of Tom. Then each Englishman invited both his mother and his teacher, and (45) is false. 


\section{Other Cases of Connectivity}

The remarks above show that the binding of a pronoun across be in copular sentences can quite naturally be accounted for without recourse to any abstract level of representation. This is a welcome result since, as discussed in Sec. 1, the positing of an abstract level to account for connectivity effects appears to make hash with the rest of the semantics of copular sentences. We have seen in Sec. 4, however, that by combining the functional question analysis with a variable-free semantics, we can adopt the Higgins/Williams/Partee semantics for copular sentences and account for their full meaning - including the binding effect - with direct interpretation.

Nonetheless, a proponent of the abstract level solution could well argue that such a level is motivated by a variety of other considerations, and not just by the binding of pronouns as in (2). Reflexives, control, and a number of other phenomena also show connectivity effects in this construction. Thus a full treatment of specificational copular sentences without recourse to an abstract level must ultimately show that these other kinds of connectivity effects can also be accounted for under direct interpretation. Obviously, to do this would take us well beyond the scope and allotted space of this paper. In closing, however, I will briefly mention as few points concerning the connectivity effects shown in (1) to show that the direct interpretation approach is certainly plausible.

Consider first the case of a reflexive within a predicative constituent (such as an AP) as in (1a). While there are many open questions about the analysis of English reflexives, there are also any number of accounts (e.g., Bach and Partee (1980), Szabolcsi (1987)) which predict that the AP in (1a) denotes the property $\lambda x\left[p r o u d-o f^{\prime}(x)(x)\right]$ - which we will call the "proud-of-self" property. (Just how the mechanisms work to ensure that this APdoes indeed have this meaning depends on the particular analysis.) If this is correct, then again the reflexive is not actually "bound by" or co-indexed to any other NP; it simply contributes a meaning such that the AP denotes the proud-of-self property. (1a) is thus straightforward under the Higgins/Williams/Partee semantics for specificational copular sentences; it just says that the proud-of-self property is a member of the (singleton) set of properties that John has. For further details, see Partee (1985) who gives the semantics for this case. It should be noted, though, that Partee stopped just short of a fully semantic account of the connectivity effect here, simply because she assumed that a reflexive must be co-indexed with its binder. But there is no real reason to make this assumption, and if we abandon it, then this connectivity effect is unproblematic.

As to the reflexive within an NP as in (1b), it has been argued quite convincingly by Kuno (1975), Zribi-Hertz (1989), Pollard and Sag (1992) and others that in fact such a reflexive does not need a binder in any c-commanding relationship to it. In fact, as these authors point out, no binder is needed at all within the same sentence:

(48) John was upset. That picture of himself in the museum had been mutilated.

These authors claim that the conditions for a "Picture Noun Reflexive" are actually determined by pragmatic and/or discourse considerations; if this line is correct then grammaticality of ( $1 b$ ) shows nothing about the need for an abstract level at which the "binder" c-commands the reflexive. As to (1c), this appears at first glance to be more problematic. However, if the typology of reflexives put forth in Pollard and Sag (1992) is correct then this too is like a "Picture Noun Reflexive" and it does not need a local and/or c-commanding antecedent. Of course these remarks are quite suggestive; one needs a full account of the discourse conditions which sanction 
such reflexives is order to have a full analysis, but the motivation for an abstract level based on these reflexives is weak, at best.

In conclusion, then, at least some connectivity effects in copular sentences are completely unproblematic. under direct interpretation, given the approach to binding argued for here. I would like to suggest, then, that the moral to be drawn from copular sentences is that any phenomenon which exhibits "unexpected" connectivity in this construction should not, in fact, be characterized in terms of two constituents which need to be in a given syntactic configuration.

\section{References}

Akmajian, A. (1970) Aspects of the Grammar of Focus in English, Ph.D. Dissertation, MIT.

Bach, E. and B. Partee (1980) "Anaphora and Semantic Structure", in J. Kreiman and A. Ojeda (eds.), CLS Parasession on Anaphora, Chicago Linguistic Society, Chicago.

Chierchia, G. (1990) "Anaphora and Attitudes De Se", in R. Bartsch et al. (eds.), Language in Action, Foris, Dordrecht.

Chierchia, G. (1993) "Questions with Quantifiers", Natural Language Semantics $1,181-234$.

Curry, H. and R. Feys (1958) Combinatory Logic, North-Holland Publishing Co., Amsterdam.

Dahl, O. (1981) "Binding Relations in Dislocated Constituents", talk presented at the Sloan Workshop on Alternatives to Transformational Grammar, Stanford University.

Dowty, D. (1992) "'Variable-Free' Syntax, Variable-Binding Syntax, The Natural Deduction Lambek Calculus, and the Crossover Constraint", in Proceedings of the 11th Meeting of the West Coast Conference on Formal Linguistics, CSLI Publications, Stanford.

Engdahl, E. (1986) Constituent Questions, Reidel, Dordrecht.

Gawron, M. and S. Peters (1990) Anaphora and Quantification in Situation Semantics, CSLI Publications, Stanford.

Ginzburg, J. (1992) Questions, Queries and Facts: a Semantics and Pragmatics for Interrogatives, Ph.D. Dissertation, Stanford.

Groenendijk, J. and M. Stokhof (1983) "Interrogative Quantifiers and Skolem Functions", in K. Ehlich and H. van Riemsdijk (eds.), Connectedness in Sentence, Discourse and Text, Tilburg Studies in Language and Literature 4, Tilburg University.

Hepple, M. (1990) The Grammar and Processing of Order and Dependency: A Categorial Approach, Ph.D. Dissertation, University of Edinburgh, Edinburgh.

Higginbotham, J. (1992) "Reference and Control", in R. Larson et al. (eds.), Control and Grammatical Theory, Dordrecht: Kluwer.

Higgins, R. (1973) The Pseudo-Cleft Construction in English, Ph.D. Dissertation, MIT. Distributed by the Indiana University Linguistics Club, Bloomington: 1976.

Hornstein, N. (1984) Logic as Grammar, MIT Press, Cambridge.

Jacobson, P. (1977) The Syntax of Crossing Coreference Sentences, Ph.D. Dissertation, U.C. Berkeley. Published by Garland Press, New York, 1981.

Jacobson, P. (1987) "Review of Gazdar, Klein, Pullum, and Sag, Generalized Phrase Structure Grammar", Linguistics and Philosophy 10, 389-426. 
Jacobson, P. (1991) "Functional Questions, Paycheck Pronouns, and Variable Binding", presented at the ASL/LSA Conference, Linguistic Society of America Summer Institute, Santa Cruz.

Jacobson, P. (1992a) "Bach-Peters Sentences in a Variable Free Semantics", in P. Dekker and M. Stokhof (eds.), Proceedings of the Eighth Amsterdam Colloquium, Institute for Logic, Language, and Computation, University of Amsterdam.

Jacobson, P. (1992b) "Antecedent Contained Deletion in a Variable Free Semantics", in C. Barker and D. Dowty (eds.), Proceedings of the Second Conference on Semantics and Linguistic Theory, Ohio State University, Columbus.

Jacobson, P. (1994) "i-within-i Effects in a Variable Free Semantics and a Categorial Syntax", in P. Dekker et al. (eds.), Proceedings of the Ninth Amsterdam Colloquium, Institute for Logic, Language, and Computation, University of Amsterdam.

Jacobson, P. (in preparation) "Toward a Variable Free Semantics", ms. Brown University.

Kuno, S. (1975) "Three Perspectives in the Functional Approach to Syntax", in Papers from the Parasession on Functionalism, Chicago Linguistic Society, Chicago.

Lakoff, G. (1965) On the Nature of Syntactic Irregularity, Harvard University Computation Laboratory Report NSF-16, Cambridge. (Reprinted as Irregularity in Syntax, Holt, Reinhart, and Winston, 1970.)

Lakoff, G. (1970) "Repartee", Foundations of Language 6, 389-422.

May, R. (1985) Logical Form: Its Structure and Derivation, MIT Press, Cambridge.

Moortgat, M. (1989) Categorial Investigations, Foris, Dordrecht.

Oehrle, R. (1990) "Categorial Frameworks, Coordination, and Extraction" in Proceedings of the Ninth Annual West Coast Conference on Formal Linguistics, CSLI Publications, Stanford.

Partee, B. (1985) "Ambiguous Pesudoclefts with Unambiguous $B e^{\text {", }}$ in S. Berman et al. (eds), Proceedings of NELS 16, GLSA, University of Massachusetts, Amherst.

Partee, B. and M. Rooth (1983) "Generalized Conjunction and Type Ambiguity", in R. Bauerle et al. (eds.), Meaning, Use, and Interpretation of Language, de Gruyter, Berlin.

Peters, S. and E. Bach (1968) "Pseudo-cleft sentences", unpublished ms., University of Texas, Austin.

Pollard. C and I. Sag (1992) "Anaphors in English and the Scope of Binding Theory", Linguistic Inquiry 23, 261-303.

Quine, W.V. (1966) "Variables explained away" in W.V. Quine, Selected Logic Papers, Random House, New York.

Reinhart, T. (1983) Anaphora and Semantic Interpretation, Croom Helm, London.

Reinhart, T. (1990) "Self Representation", presented at the Princeton Conference on Anaphora, Princeton.

Rodman, R. (1976), "Scope Phenomena, 'Movement Transformations', and Relative Clauses", in B. Partee (ed.), Montague Grammar, Academic Press, New York.

Ross, J.R. (1972) "Act" in D. Davidson and G. Harman (eds.), Semantics of Natural Language, Reidel, Dordrecht.

Steedman, J. (1987) "Combinatory Grammars and Parasitic Gaps", Natural Language and Linguistic Theory 5, 403-440. 
Szabolcsi, A. (1987) "Bound Variables in Syntax: Are There Any", in J. Groenendijk et al. (eds.), Proceedings of the 6th Amsterdam Colloquium, ITLI, University of Amsterdam.

Szabolcsi, A. (1992), "Combinatory Categorial Grammar and Projection from the Lexicon", in I. Sag and A. Szabolcsi (eds.), Lexical Matters, CSLI Publications, Stanford.

Williams, E. (1983) "Semantic vs. Syntactic Categories", Linguistics and Philosophy 6, 423-446.

Zribi-Hertz, A. (1989) "Anaphor Binding and Narrative Point of View: English Reflexive Pronouns in Sentence and Discourse", Language 65, 695-727. 